\title{
Effects of soil covers on air and soil temperature and on growth and yield of sugar-beets
}

\author{
L. Sibma \\ Centre for Agrobiological Research (CABO), Wageningen, Netherlands
}

Received 28 January 1983; accepted 15 June 1983

Key-words: sugar-beet, plastic cover, soil temperature, air temperature, sugar yield, sugar content, leaf area, factory output

\section{Summary}

From 1976-1979 field experiments with sugar-beets were done in which screening the soil in various ways with transparent plastic sheet. From the sowing date until some time after emergence soil and air temperatures were investigated. The temperature measured at $7 \mathrm{~cm}$ depth in the rows was closely associated with the width of the strips covering the rows. Perforated plastic was less effective. Increasing the soil temperature alone did not increase the growth or the yield of sugar-beets. When the higher soil temperature was combined with a higher ambient air temperature the development of the crop was advanced by 10-14 days. The improvement in the microclimate positively affected the dry matter production of the beets during the growing period and the final sugar yield. The higher final sugar yields were more often the result of the higher beet weight than of a higher sugar content. There were no changes in the factory output such as might have resulted from reductions in $\mathrm{K}, \mathrm{Na}$ or $\alpha$-amino $\mathrm{N}$. No evidence was found of high temperature on leaf damage, increases in the number of bolters, or changes in dry matter distribution in any of the experiments.

\section{Introduction}

The leaf growth of sugar-beet in spring is retarded because average air temperatures are much lower than the optima for both germination and leaf expansion (Dubetz et al., 1962; Milthorpe \& Terry, 1967; Radke \& Bauer, 1969). Thus a closed crop canopy intercepting most of the available radiation is not formed until the second half of June. It takes till mid-August that maximum number of leaves and leaf area per unit land occurs. At that time only $50-60 \%$ of the final storage root weight is reached (Boonstra, 1942; Schreiber \& Ferguson, 1965). Relationships between the yield of sugar-beets and total radiation intercepted have been demonstrated in studies employing different dates of sowing or of transplanting from the glasshouse (Scott \& Bremner, 1966; Scott \& Jaggard, 1978; Sibma, 1970). 
Covering various crops with transparant plastic sheet immediately after sowing in spring has been found to give an advantage of seven to ten days in leaf development (Balif, 1979; Sibma, 1977; Sondern, 1975; Schreiber \& Ferguson, 1965). Data on the extent to which the microclimates in the above- and below-ground zone is altered and on the effect of soil covers on yield are, however, rather limited. In relation to technical equipment, cost and environmental problems, it is important to know what degree of soil coverage will consistently increase yields. On the other hand, it is doubtful whether soil heating only is sufficient to advance the date by which a closed crop is attained.

To study the effects of soil coverage on leaf development, growth and yield of sugar-beets field experiments were done with different types of soil covers.

\section{Materials and methods}

\section{Cultural techniques}

The experiments were done in the years 1976-1979 with sugar-beet (cultivar Monohil) grown on a reclaimed calcareous marine clay-soil in the North-East Polder. For all crops fertilizer was applied before drilling in the spring to ensure adequate nutrition. The crops were precision-drilled with $17 \mathrm{~cm}$ between plants in the row and 50 $\mathrm{cm}$ between rows to give a target population of 80000 plants ha $\mathrm{h}^{-1}$. Immediately after drilling $4 \mathrm{~kg} \mathrm{ha}^{-1}$ of Pyramin was sprayed to control weeds. In most years soil water supply is adequate; however, in the very dry season of 1976 , a total of $70 \mathrm{~mm}$ of water was applied by sprinkler irrigation on 2 occasions during July for preventing water shortage.

\section{Experimental techniques}

In 1976 rows were covered with tunnels made from $0.1-\mathrm{mm}$ thick transparant plastic sheet, which were $12.5 \mathrm{~cm}$ high and $25 \mathrm{~cm}$ wide, covering $50 \%$ of the soil surface and compared with uncovered rows.

In 1977 a third treatment was added in which strips of the transparent plastic, 39 $\mathrm{cm}$ wide, were placed lengthwise over the rows. The strips were held in position with iron tubes at the sides and covered $78 \%$ of the soil surface. Immediately after emergence, a hole was made in the plastic sheet above the plants, so that the tops were subjected to the outside temperature, while the roots experienced a higher temperature than normal.

In the 1978 experiment a study was made of the effect of the plastic tunnels on plants transplanted into the field at the same time as the directly drilled control plots. This permitted transplanted and sown plants to be compared. The transplanted plants were grown in paper pots ${ }^{1} 2 \mathrm{~cm} \times 2 \mathrm{~cm} \times 13 \mathrm{~cm}$ deep from February onward in a glasshouse and were planted out in the field on the same day that the normal crop was sown.

The 1979 experiment included a second cultivar, Solorave, which was expected to produce more top than Monohil and to remain green for longer. This experiment

1 Made by Nippon Tensai Seito Kabushiki Kaisha (Martens et al., 1974). 
Table 1. Treatments in the experiments in 1976/1979.

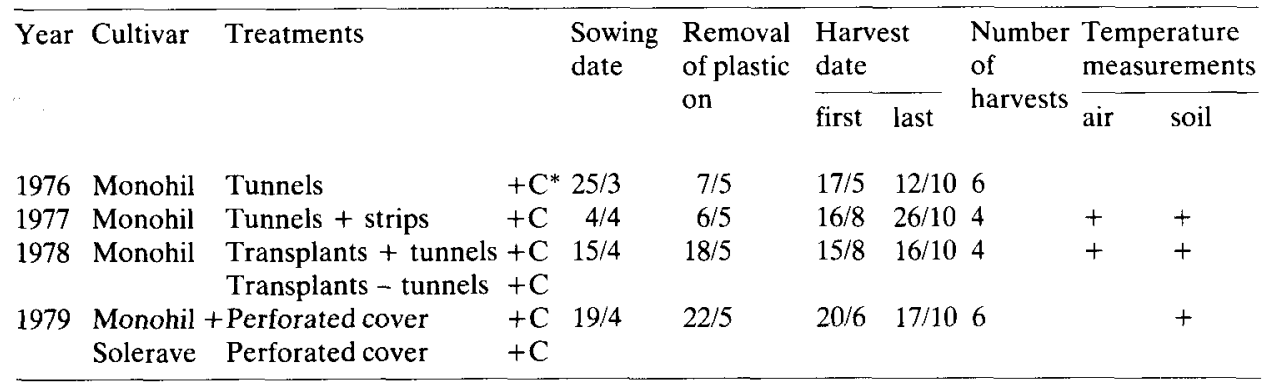

* $\mathrm{C}=$ normally treated sugar-beets.

was carried out as a split-plot design with 6 replicates. The four treatments $(2$ cultivars, covered or not covered) were applied to main plots of 6 units, each unit representing a different harvest date. A unit consisted of 4 rows of $8 \mathrm{~m}$ with an interrow spacing of $0.5 \mathrm{~m}$. One half of the main plots was covered over its whole area with $0.05-\mathrm{mm}$ thick plastic sheet. This plastic was perforated with $1-\mathrm{cm}$ holes $(475 \mathrm{per}$ $\mathrm{m}^{2}$ ). Plants grew under this plastic sheet till 22 May.

Table 1 summarizes the dates of drilling, which were when the different treatments were applied, the dates when the plastic cover was removed, dates of the first and last harvests, the number of intermediate harvests and indication of recording soil or air temperatures.

Air temperatures $10 \mathrm{~cm}$ above ground were recorded in 1977 and 1978 but not in 1979; soil temperatures $7 \mathrm{~cm}$ deep were measured in all three years. Two thermocouples per treatment were used for the soil temperature and two thermocouples per treatment for air temperature in the middle of strips. All temperature data were continuously recorded on a 16 point Honeywell chart recorder. The accumulated temperature ( $\mathrm{T}$-sum) was calculated from the average of the daily maximum and minimum temperatures.

In 1979, in the surrounding sugar-beets outside the experiment, but near by, another small experiment was done. A number of unperforated plastic strips were plaved lengthwise over the rows. These strips varied in width, in classes of $12.5 \mathrm{~cm}$, from 0 to $50 \mathrm{~cm}$, so that $0,25,50,75$ or $100 \%$ of the soil was covered. Soil temperatures at $7 \mathrm{~cm}$ depth were measured from 19 April to 22 May in the middle of the strips. No yields were measured.

Unless stated otherwise each experiment had 3 replicates with a net plot size of 2 $\mathrm{m} \times 5 \mathrm{~m}=10 \mathrm{~m}^{2}$. In the intermediate and final harvests 4 rows of $5 \mathrm{~m}$ length (about 80 plants) were collected. The shoots and roots of each 10th plant were sampled for dry matter content and in the last two harvests for chemical composition also.

The sugar content in $\mathrm{g} \mathrm{kg}^{-1}$ fresh weight and $\mathrm{K}, \mathrm{Na}$ and $\alpha$-amino $\mathrm{N}$ in mmol kgfresh weight were analysed after van Gelder (1974), each year in the sugar-beets of the last two harvests, except for 1976, when this analysis was done for the last harvest only. 
Sugar content is one of the main parameters for the quality of sugar-beets. Because of losses as molasses etc., part of the sugar is commercially available. The factory losses are positively related to the $\mathrm{K}, \mathrm{Na}$ and $\alpha$-amino- $\mathrm{N}$ contents. The commercial availability (yield, factory output) was calculated by Reinefeld's equation (Reinefeld et al., 1974), adopted by Holsbeek \& Scheys (1981):

$$
Y=\frac{R-\left[0.343(\mathrm{~K}+\mathrm{Na})+0.094 \mathrm{~N}+2.9^{*}\right]}{R}
$$

in which $Y=$ the yield of white sugar as a ratio of the sugar content

$\mathrm{R}=$ the sugar content $\left(\mathrm{g} \mathrm{kg}^{-1}\right)$

$\mathrm{K}, \mathrm{Na}$ and $\alpha$-amino $\mathrm{N}$ in $\mathrm{mmol} \mathrm{\textrm {kg } ^ { - 1 }}$ beet

\section{Results}

\section{Soil and air temperatures}

In the period 7 April-10 May 1977 the accumulated heat units for air temperature, the T-sum $\left({ }^{\circ} \mathrm{C}\right.$-days) were 125 units higher under the tunnels in comparison with the control (Fig. 1a). This was thus equivalent to an average increase in the daily temperature of $4{ }^{\circ} \mathrm{C}$. The results derived from thermocouple measurements were in good agreement with those calculated from data of a near by weather station. An average $\mathrm{T}$-sum was calculated from the weather station air temperatures available for the years 1964-1982. The 10 May value of this average T-sum (which is somewhat higher than in 1977) is also indicated in Fig. 1a.

The differences in T-sum for the soil temperature were smaller than those observed for the air temperature. The soil temperature under the strips was found to be higher than under the tunnels. The data in 1978 (not presented) were similar to those in 1977; in both years the wider strips had a greater soil heating effect than the smaller tunnels. This suggested that the soil heating effect depended on the width of the strips of soil screened.

The importance of soil area covered with plastic was further investigated in 1979 when the temperature at $7 \mathrm{~cm}$ depth was measured under plastic strips of different widths, but without perforations. From 27 April to 22 May this was done on clay soil in the North-East Polder, simultaneously with the measurements under the perforated plastic. The $\mathrm{T}$-sums obtained confirmed results from a similar experiment conducted earlier that spring on a sandy soil in Wageningen and showed that the temperature increase in the soil was closely dependent on the width of the strips. Fig. 2a shows the increase in these T-sums of 100,50 and $0 \%$ soil cover. Since the yield differences in 1979 were obtained by application of perforated plastic, the Tsum of these soil temperatures measured under plastic in the whole plots is also shown. It may be concluded that the heating effect was proportionnally lower with the width of the strips. A decrease to half the row distance decreased the heating effect to about $50 \%$. Small perforations have a similar effect, though to a lesser extent. The final value of the average T-sum over the period 27 April-22 May over the

\footnotetext{
${ }^{*}$ Factor in $\mathrm{g} \mathrm{kg}^{-1}$.
} 


\section{EFFECTS OF SOIL COVERS ON SUGAR-BEETS}
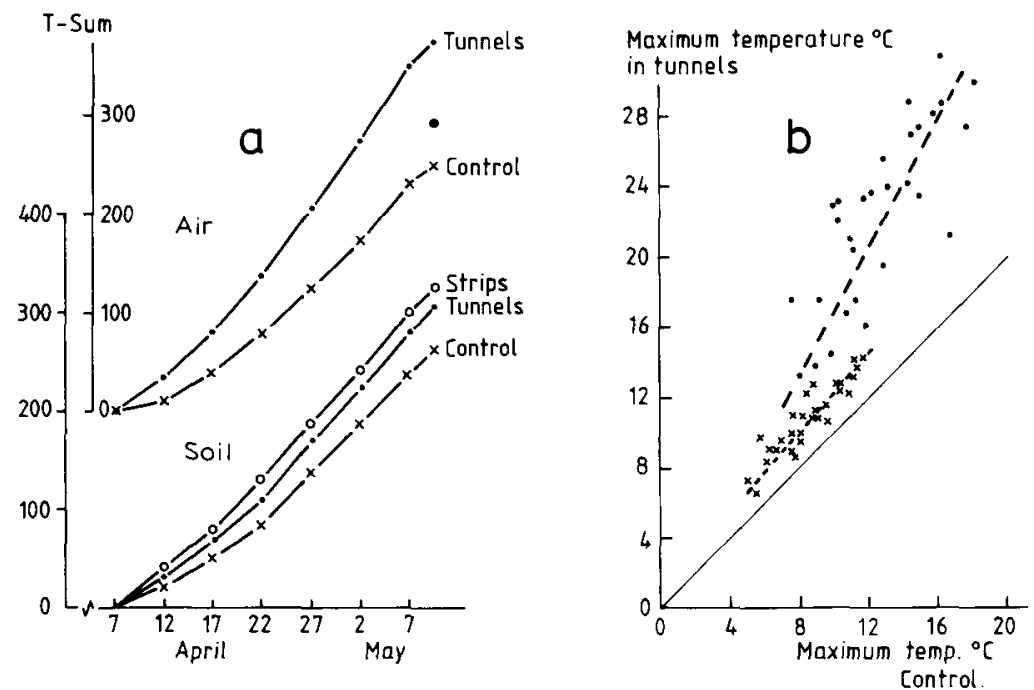

Fig. 1a. Trend in the temperature sum (T-sum) at $10 \mathrm{~cm}$ height (air) and $7 \mathrm{~cm}$ depth (soil) per 5 days in the period from 7 April until 10 May 1977 under tunnels, strips and control. $=$ average T-sum of the air of this period in the years 1964-1982.

Fig. 1b. Relation between maximum temperatures outside and inside the tunnels of the soil $(x)$ and air (O).

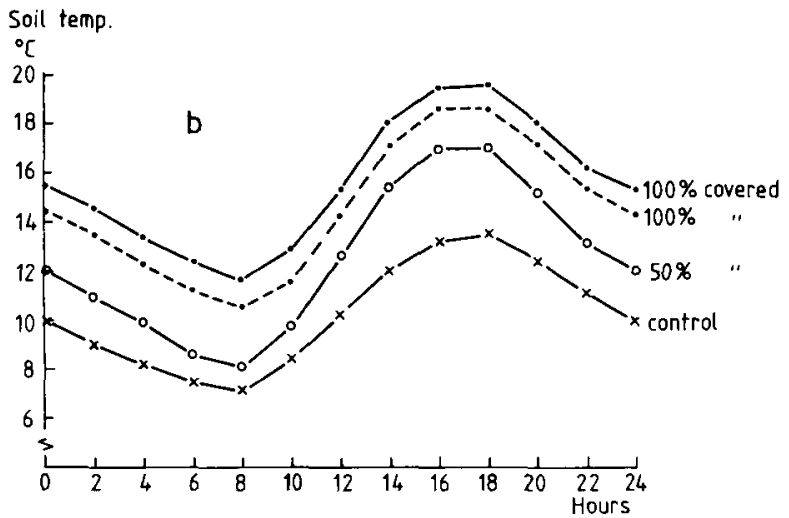

Fig. 2a. T-sum of the period 27 April-22 May 1979.

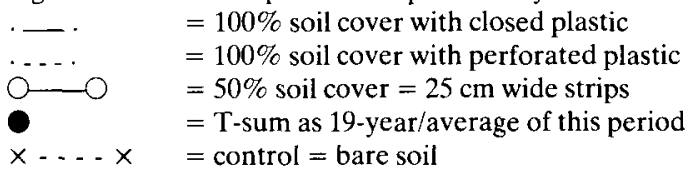

Fig. 2b. Trend in the soil temperature at $7 \mathrm{~cm}$ depth, as an average per 2 hours of the same treatments as in Fig. 2a in the period 27 April-22 May 1979.

Neth. J. agric. Sci. 31 (1983) 
years 1964-1982 demonstrates that in 1979 the temperature was also somewhat lower than normal.

It is shown in Fig. 2a that from some days after drilling until the removal of the plastic the T-sum in 1979 was increased by 125 units in 25 days. Fig. 2b shows the diurnal change in the soil temperature of the same treatments as shown in Fig. $2 a$, as an average of all the days in the relevant period, plotted per two hours. Fig. $2 b$ demonstrates that this increase is almost constant at $7 \mathrm{~cm}$ depth over the 24 hours.

The fluctuations in air temperature measured in 1977 and 1978 in the tunnels were much greater than those in the soil temperature and, moreover, were more complex because they depend more on changes in cloudiness, wind speed, radiation, etc. The number of measurements is too small to establish these relationship separately.

The possible risk to the plants of unfavourably high maximum temperatures on sunny days when grown under plastic is a particularly important consideration. Fig. 1b shows the daily maximum air temperatures inside the tunnels plotted against the daily maximum air temperatures outside the tunnels in the period 7 April-10 May. These results show that increases in air temperature were greatest when ambient temperatures outside the tunnels were high (i.e. the angle of the line is greater than $45^{\circ}$ ). Effects on soil temperature were of the same order at all outside temperatures within the range studied.

\section{Yields and chemical composition}

Fig. 3 shows the increase in dry matter of covered and non-covered sugar-beets in the form of growth curves. In the interest of clarity the 1977 and 1978 yields have been plotted out in the separated Fig. $3 b$ and $3 c$.

In 1976, a year with high irradiances and the largest dry matter yields, the tunnels gave an initial yield advantage and this was maintained throughout. Tunnels also gave a considerable yield increase in 1977, but data from harvests show in Fig. 3b that plants in which the aerial parts were exposed to normal air temperatures shortly after emergence did not yield any more than control plants. This happened in spite of the fact that soil temperatures under the strips were higher than under the tunnels (see Fig 1a). The conclusion must be that an increase in soil temperature is not, in itself, sufficient to bring about a yield increase in sugar-beet.

In 1978 the dry matter yields of non-covered transplanted sugar-beets presented in Fig. $3 c$ were higher than those of the sugar-beets sown at the same time. In turn, transplanted beets yielded more when grown in plastic tunnels. Fig. $3 \mathrm{c}$ shows that the combined effects of transplanting and of the tunnels led to a substantial yield increase when compared with the controls. This was the same for the sugar yields presented in Table 2.

The relatively high sugar yields are brought about by a combination of high dry matter yields and a reasonable sugar content (Table 2). The $\mathrm{K}, \mathrm{Na}$ and $\alpha$-amino $\mathrm{N}$ concentrations are not significantly affected by the treatments.

The factory output presented in Table 2, as a measure for the quality, hardly seemes to be influenced by the treatments and if so more times negatively than positively. 

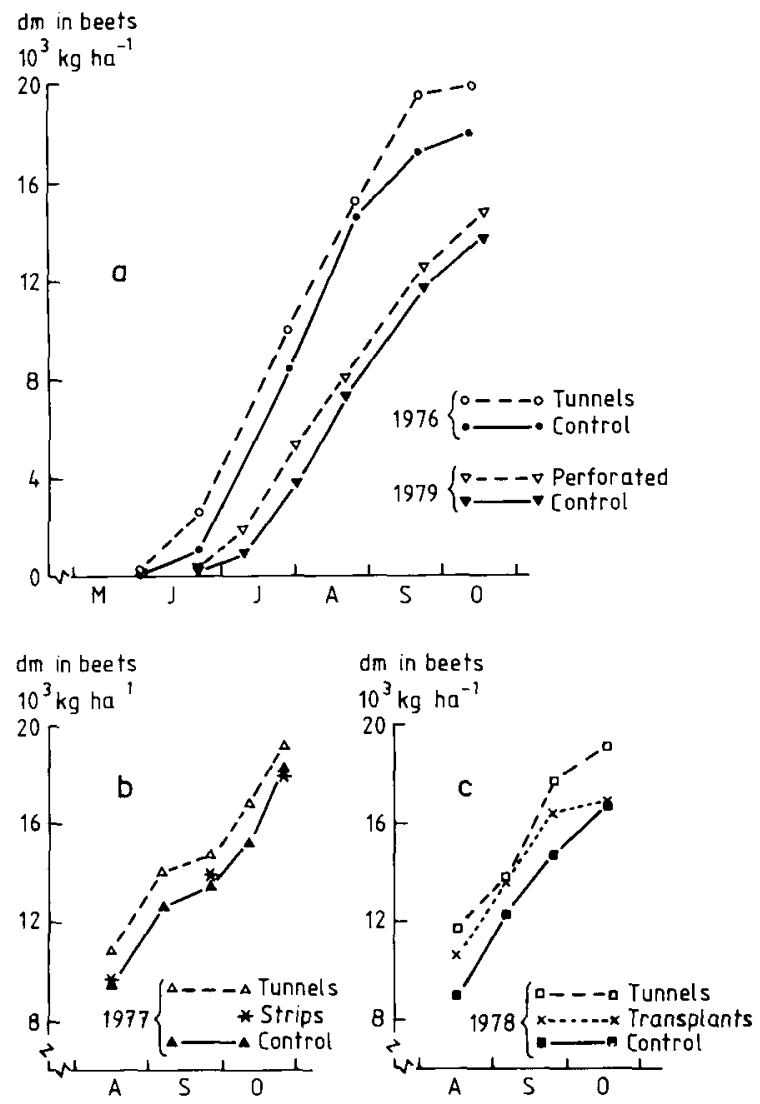

Fig. 3. Comparison of beet dry matter $\left(10^{3} \mathrm{~kg} \mathrm{ha}^{-1}\right)$ as growth curves in the years 1976 and 1979 (a), 1977 (b) and 1978 (c) with or without plastic covers.

\section{Discussion}

Increasing the ambient temperature within a range of $6-24^{\circ} \mathrm{C}$ improves germination and initial growth (Dubetz et al., 1962; Milthorpe \& Terry, 1967; Radke \& Bauer, 1969). The optimum temperature of about $24^{\circ} \mathrm{C}$ for growth of the whole plant decreases as the plant grows larger (Dubetz et al., 1962; Milthorpe \& Terry, 1967; Radke \& Bauer, 1969). In spring the soil and air temperatures in the Netherlands are much lower than this optimum. Fig. 1 shows that the increase in T-sum, under tunnels, from 7 April until 10 May in 1977 was 125 units for the air and about 80 units for the soil. These changes were equivalent to mean daily increases in air and soil temperatures of about 4 and $2.5^{\circ} \mathrm{C}$ respectively. Any treatment which raises soil and air temperature in this period will improve initial growth and with it plant yield.

Improving the microclimate by tunnels in 1977 caused a yield increase of some $10 \%$ in dry weight and sugar yield of beets (Fig. 3 and Table 2). In the same experiment the plastic strips with holes above the plants made after emergence did not af- 
Table 2. The number of plants, sugar yield and chemical composition of the sugar-beets at the last 2 harvests.

\begin{tabular}{|c|c|c|c|c|c|c|c|c|c|c|}
\hline \multirow[t]{3}{*}{ Harvest date $\rightarrow$} & \multicolumn{2}{|l|}{1976} & \multicolumn{2}{|l|}{1977} & \multicolumn{2}{|l|}{1978} & \multicolumn{4}{|c|}{1979} \\
\hline & \multirow[t]{2}{*}{21 Sept } & \multirow[t]{2}{*}{$12 \mathrm{Oct}$} & \multirow[t]{2}{*}{$11 \mathrm{Oct}$} & \multirow[t]{2}{*}{$26 \mathrm{Oct}$} & \multirow[t]{2}{*}{$25 \mathrm{Sep}$} & \multirow[t]{2}{*}{16 Oct } & \multicolumn{2}{|c|}{24 Sep } & \multicolumn{2}{|c|}{$17 \mathrm{Oct}$} \\
\hline & & & & & & & $\mathbf{M}^{*}$ & $\mathrm{~S}^{*}$ & $\mathrm{M}$ & $S$ \\
\hline \multicolumn{11}{|c|}{ Plant density $\left(10^{3} h a^{-1}\right)$} \\
\hline Soil covered & \multirow{2}{*}{\multicolumn{2}{|c|}{$\begin{array}{r}94 \\
100\end{array}$}} & \multirow{2}{*}{\multicolumn{2}{|c|}{$\begin{array}{l}88 \\
87\end{array}$}} & \multicolumn{2}{|r|}{102} & \multicolumn{4}{|c|}{87} \\
\hline Control & & & & & & 98 & & & 77 & \\
\hline \multicolumn{11}{|c|}{ Sugar yield $\left(10^{3} \mathrm{~kg} \mathrm{ha}^{-1}\right)$} \\
\hline Soil covered & 15.1 & 14.9 & 11.5 & 13.3 & 12.7 & 13.8 & 9.2 & 9.7 & 11.2 & 11.0 \\
\hline Control & 12.8 & 13.9 & 10.4 & 11.9 & 10.5 & 12.0 & 9.2 & 8.8 & 11.0 & 10.0 \\
\hline Yield increase (\%) & 11.8 & 7.2 & 9.7 & 11.9 & 20.8 & 15.0 & -0.5 & 10.3 & 2.5 & 9.4 \\
\hline $\mathrm{P}$ & $<0.01$ & n.s. & n.s. & $<0.05<$ & $<0.01$ & $<0.01$ & $\mathrm{n} . \mathrm{s}$ & $<0.01$ & n.s. & $<0.01$ \\
\hline \multicolumn{11}{|c|}{ Sugar content ( $\mathrm{kg}^{-1}$ fresh weight) } \\
\hline Soil covered & 175 & 166 & 173 & 175 & 163 & 166 & & 170 & & 170 \\
\hline Control & 167 & 167 & 176 & 177 & 160 & 164 & & 166 & & 166 \\
\hline \multicolumn{11}{|l|}{$K\left(\right.$ mmol $\mathrm{kg}^{-1}$ beet $)$} \\
\hline Soil covered & & 62.0 & 71.0 & 63.0 & 54.5 & 57.0 & & 58.5 & & 57.7 \\
\hline Control & & 60.1 & 65.1 & 62.0 & 53.4 & 61.5 & & 59.2 & & 58.1 \\
\hline \multicolumn{11}{|l|}{$\mathrm{Na}\left(\mathrm{mmol} \mathrm{kg}^{-1}\right.$ beet $)$} \\
\hline Soil covered & & 5.2 & 5.4 & 4.1 & 3.6 & 3.7 & & 4.7 & & 3.8 \\
\hline Control & & 4.8 & 4.4 & 4.1 & 3.0 & 3.9 & & 5.5 & & 4.5 \\
\hline \multicolumn{11}{|c|}{$\alpha$-amino $N\left(\right.$ mmol $\mathrm{kg}^{-1}$} \\
\hline beet) & & 33.3 & 22.1 & 27.1 & 22.7 & 20.8 & & 12.7 & & 14.5 \\
\hline Control & & 31.8 & 18.2 & 20.7 & 22.0 & 22.8 & & 13.3 & & 15.4 \\
\hline \multicolumn{11}{|l|}{ Factory output $\left(\mathrm{g} \mathrm{g}^{-1}\right)$} \\
\hline Soil covered & & 0.833 & 0.819 & 0.837 & 0.847 & 0.845 & & 0.848 & & 0.850 \\
\hline Control & & 0.832 & 0.838 & 0.844 & 0.848 & 0.832 & & 0.840 & & 0.865 \\
\hline
\end{tabular}

${ }^{*} \mathrm{M}=$ Monohil; $\mathrm{S}=$ Solorave.

fect the yield (Fig. 3b), although the soil temperature was increased more by the strips than by the tunnels (Fig. 1a). This implies, at least with sugar-beets, that increases in the soil temperature alone do not improve yields. So, heating the soil with hot water tubes, as an application of waste heat from electric power stations cannot advance the development of a leaf canopy of sugar-beets in spring. This agrees also with the observations of Sondern (1975 and 1977), who suggested that an effect of soil heating is only to be expected when the ambient air temperature is sufficiently high, and that this effect is also dependent on the species.

The use of narrower plastic strips covering only the rows, might facilitate the practical application, because of the lower cost and fewer drawbacks for environmental pollution with plastic. Comparisons showed that both narrow tunnels and narrow strips increased soil temperature less than wider strips. Measuring the soil 
temperature at a depth of $7 \mathrm{~cm}$ along a transect from the middle of a plastic covered area showed a $5{ }^{\circ} \mathrm{C}$ drop in temperature from $30 \mathrm{~cm}$ within the margin of the plastic to $15 \mathrm{~cm}$ outside, suggesting a gradient of heat loss towards the margins of the plastic strips. On the other hand it was found that the T-sum for air temperature in the tunnels was not unfavourably influenced by the narrowness of the tunnels.

Balif (1979) stated that on the colder soils in France the difference in dry matter yield caused by soil covering in spring, was at a maximum during linear growth in July and August and decreased at later measurements. The growth curves of our experiments in 1976 and 1979 confirm that the differences initially increase until a closed crop canopy is attained. This is to be expected, because increases in leaf area lead to increased light interception and greater growth. In these experiments the yield curves of the comparable treatments are parallel up to the end of the growing period. The initial differences in LAI in our experiments were not maintained once the canopy had closed, although in all four observation years the LAI attained a maximum sooner under the plastic covers. This contrasts with observations of Balif (1979), who obtained consistently higher LAIs after plastic covers than in control plants. This may be because the plastic covers remained in situ for longer and helped to reduce evaporation losses.

At each harvest the ratios of dry matter in the beet to the total dry matter was always higher on the treated plots. This was not the result of a change in dry matter distribution, but of the physiological age of the beets. When this ratio was plotted against total dry matter present and not against the dates, no difference was observed between the treatments.

Leaf damage caused by too high temperatures under the plastic covers on sunny days was not observed in any of the years. Fig. 1b shows that when the temperature outside the tunnel rose to $14-18{ }^{\circ} \mathrm{C}$ the optimum temperature of $24{ }^{\circ} \mathrm{C}$ was exceeded inside the tunnel on most days. It is emphasised that the period 7 April-10 May 1977 was somewhat colder than normal. So some risk of too high temperatures under the plastic cover may be expected in years with normal temperatures or even higher than normal. In 1979, hail storms after removing the plastic damaged more leaves of the beets, which had emerged under the plastic, because the beets in these treatments had more foliage. Undoubtely this levelled the yield effect of the treatment in 1979.

The percentage of bolters was observed and found to be very low in all the experimental years. No difference was observed between treatments with and without plastic covers.

No distinct effect was found on the components $\mathrm{K}, \mathrm{Na}, \alpha$-amino $\mathrm{N}$ and sugar content separately (Table 2). All the components together, as given in the factory output, were more often affected adversely than favourably by the use of plastic covers. In 1979 the varieties hardly differed in chemical composition, except for the Na-content in cv. Solorave, which was somewhat higher. Table 2 shows the averaged chemical composition of the two cultivars.

The yields in the sunny year 1976 were highest of all the experimental years, which corresponds well with the data obtained earlier (Sibma, 1970); that is, on soils with an optimal water and mineral supply the yields are closely related to the 
amount of radiation intercepted during the growing period. The yield increase in 1976 was about the same as in other years when yields were lower, which shows that the yield level is neither decisive nor restrictive to further yield improvements. However, these yield effects may only be expected when other growth factors are not limiting yields.

The highest sugar yields were produced in 1976 with relatively low amounts of dry matter in the foliage, which indicates that sugar-beets often invest more dry matter in the foliage than required for attaining optimum light interception and maximum sugar yields. To what extent a rather high LAI during the season is required to intercept sufficient light at the end of the growing period is subject of further study.

\section{Acknowledgement}

I am grateful to Ir N. M. de Vos for useful suggestions. Thanks are due to $\mathrm{Mr}$ C. J. Mol who worked out the temperature recordings. The technical assistance of Miss M. J. de Kock and Mr G. J. van der Sluis is acknowledged.

\section{References}

Balif, J. L., 1979. The effects of photodegradable plastic mulch on growing sugar beet on chalky soil in Champagne. Plasticultura 43: 21-30.

Boonstra, A. E. H. R., 1942. Rasverschillen bij suikerbieten. VI. Mededelingen van het Instituut voor Suikerbietenteelt 2: 13-95.

Dubetz, S., G. C. Russel \& D. T. Anderson, 1962. Effect of soil temperature on seedling emergence. Can. J. Plant Sci. 42: 481-487.

Gelder, W. M. J. van, 1974. Toelichting behorend bij de analyse-resultaten van suikerbieten 74/90/100 $\mathrm{dB}$. Stichting voor Plantenveredeling, Wageningen.

Holsbeek, W. F. \& I. Scheys, 1981 . Bodemgeschiktheid en optimale voedingscondities voor kwaliteitssuikerbieten. Landbouwtijdschrift 34 (1): 17-33.

Martens, M., R. van Stallen \& A. Vigoureux, 1974. Het planten van bieten een al of niet renderend onderzoek? Driemaandelijkse publikatie van Belgisch Instituut tot verbetering van de biet 42 (3): 103-120.

Milthorpe, F. L. \& N. Terry, 1967. The influence of temperature and light on the growth of sugar beet. Institut International de Recherches Betteravières Vol. 2 (4): 216-223.

Radke, J. K. R. E. Bauer, 1969. Growth of sugar beets as affected by root temperatures. Agrar. J. 61: 860-863.

Reinefeld, E. von, Emmerich \& G. Baumgarten, 1974. Zur Voraussage des Mellassezuckers aus Rübenanalysen. Zucker 27 (1): 2-12.

Schreiber, K. \& A. C. Ferguson, 1965. Effect of growth regulators on yield and quality of sugar beets. $J$. Am. Soc. Sugar Beet Technologists 14 (1) 67-74.

Scott, R. K. \& P. M. Bremner, 1966. The effect on growth, development and yield of sugar beet of extension of the growth period by transplantation. J. agric. Sci. 66: 379-389.

Scott, R. K. K. Jaggard, 1978. How the crop grows from seed to sugar. British Sugar Beet Review 46 (4): 19-22.

Sibma, L., 1970. Relation between total radiation and yield of some field crops in the Netherlands. Neth. J. agric. Sci. 18: 125-131.

Sibma, L., 1977. Maximization of arable crop yield in the Netherlands. Neth. J. Agric. Sci. 25: 278-287.

Sondern, A. J., 1975. Boerderij/Akkerbouw 24 februari-1 maart.

Sondern, A. J., 1977. Soil warming in the open. Institute of Agricultural Engineering, Research Report $77-5$. 